\title{
WHAT SETS THE WIDTH OF A RIVER?
}

PRePrint, COMPILED JaNUARY 17, 2020

\author{
Kieran B.J. Dunne ${ }^{1, t}$ and Douglas J. Jerolmack ${ }^{1,2}$ \\ ${ }^{1}$ Department of Earth \& Environmental Science, University of Pennsylvania, Philadelphia, Pennsylvania, USA \\ ${ }^{2}$ Department of Mechanical Engineering \& Applied Mechanics, University of Pennsylvania, Philadelphia, Pennsylvania, USA
}

\begin{abstract}
Alluvial rivers are formed by, and are an expression of, the water and sediment that they convey. They are the primary arteries of water and nutrients on land, making them the lifeblood of communities and commerce. While a myriad of environmental and geological factors have been proposed to control alluvial river size, near-universal scaling relations between channel geometry and discharge suggest a common organizing principle. Here we combine analysis of a global dataset with a field study to support a simple hypothesis: river geometry adjusts to the threshold fluid entrainment stress of the most resistant material lining the channel. This threshold condition describes the averaged hydraulic state of natural rivers, and is compatible with dynamics; erosion and deposition on channel banks, associated with meandering, for example, represent higher-order variations in fluid stress around the mean state. This greatly extends the applicability of threshold channel theory, which was originally developed to explain straight gravel-bedded rivers with uniform grain size and stable banks. We show how increasing the relative threshold of bank to bed material leads to a proportionate reduction in channel width and increase in channel depth; in this manner, muddy banks encourage sand-bedded rivers to adopt a meandering (rather than braided) morphology. The parsimonious "threshold-limiting material" model provides guidance for river management and restoration practices, and may aid in the reconstruction of past climates on Earth and other planetary bodies using alluvial river deposits.
\end{abstract}

\section{MAIN}

What controls the width of a river? Despite the need of channel design principles for river management and restoration [1, 2], robust scaling relations between channel shape and discharge [3], and the rapid development of sophisticated numerical models that simulate landscapes [4], this fundamental question remains unanswered [5]. When water flows over a granular medium it spontaneously channelizes. Erosion widens the channel until eventually the fluid shear stress everywhere along the boundary, $\tau_{b}$, is equal to the threshold for particle entrainment, $\tau_{c}$ [6]. The solution for the stable geometry (i.e., width and depth) of a threshold channel is well known, and forms the basis for canal design [7]. It has long been recognized, however, that natural rivers are not canals [8]. Alluvial rivers transport sediment, and this transport ceaselessly remolds the channel [9]. These dynamics are reproduced in laboratory experiments when sediment is continuously fed to the river [10]. As a first step toward understanding the shape of natural rivers, Parker [8] proposed a mechanistic solution for the geometry of an idealized model system: a straight and trapezoidal channel with stable (non-eroding) banks, lined with uniform coarse (gravel) material. The key component of his model was the explicit treatment of turbulent diffusion, which determines the lateral stress profile across the channel. This allows for stable banks with $\tau_{b} \leq \tau_{c}$, while accommodating transport in the channel center where $\tau_{b} \approx 1.2 \tau_{c}$ (Fig. 1C). The latter provides a closure scheme that, along with mass and momentum conservation for the fluid (Supplementary Materials), allows one to derive a simplified set of "regime equations" that predict the channel bankfull width, $W_{b f}$, and depth, $H_{b f}$, (Fig. 1C), as a function of specified hydraulic variables:

$$
W_{b f}=\frac{Q_{b f} S}{C_{f} g^{1 / 2}\left(\frac{1.2 \tau_{c}}{\rho g}\right)^{3 / 2}},
$$

and

$$
H_{b f}=\frac{1.2 \tau_{c}}{\rho g S},
$$

where $Q_{b f}, S, C_{f}, g$, and $\rho$ are the bankfull discharge, slope, empirical friction factor, acceleration due to gravity, and density of water, respectively (Fig. 1C; see Methods). Some researchers have suggested that additional factors such as sediment supply, vegetation, and other variables not considered in the Parker model must also play a role in determining the geometry of alluvial

\footnotetext{
*dengjiamin@gmail.com

†Present Address: Department of Earth, Environmental, and Planetary Sciences, Rice University, Houston, Texas, USA 
rivers $[11,12]$. Nonetheless, the near-threshold closure has been shown to describe hydraulic geometry trends in natural gravel-bed rivers (here defined as having a median bed-sediment diameter, $\left.D_{50}>1 \mathrm{~cm}\right)[13,6,14]$. Rivers with fine-grained $\left(D_{50}<1 \mathrm{~cm}\right)$ beds, however, do not follow the near-threshold condition. Bankfull flow conditions typically correspond to $\tau_{b} / \tau_{c}>>1$, meaning that bed-material sediment is also well suspended in the flow [15] - a condition that is not compatible with stable, threshold banks. Mechanics-based solutions fail to capture hydraulic geometry trends of natural rivers [16]. In their place, a variety of heuristic channel closure schemes have been proposed and debated [12,17]. Recently it has been noted, however, that the hydraulic geometry scaling relations of sand-bed rivers follow that of gravel-bed rivers, but with an offset that may be explained by a larger formative shear stress [18]. We have hypothesized that this deviation results due to a handoff from bed to bank control [19], and proposed a generalization of the Parker closure that we call the "threshold limiting material" model. It states that river geometry adjusts to the threshold fluid entrainment stress of the most resistant material lining the channel perimeter. For gravel-bed rivers, the entrainment threshold of bed sediment is larger than that of (likely) cohesive and/or vegetated river banks [19]. Sand, however, has the lowest entrainment stress; typically cohesive and/or vegetated banks have substantially higher entrainment stresses than the bed. We posit that the cross-sectional geometry of fine-grained rivers is set by the threshold stress of cohesive bank-toe material, which forms the structural anchor of the river bank (Fig. 1) [19]. Unfortunately, published studies rarely if ever report estimates of $\tau_{c}$ for bank-toe material, due to the difficulty of predicting and measuring the entrainment threshold of cohesive sediment [20]. Thus, the threshold limiting material model has not yet been tested.

The assumptions of the Parker model [8] appear to be incompatible with natural gravel rivers that are typically sinuous, with heterogeneous bed and bank materials, and variable discharge for which bank erosion and deposition are common. We suggest that there are two factors that explain this apparent paradox. First is that gravel has a larger entrainment threshold than typical bank materials such as mud [19]; river-bank composition likely influences the rates and style of bank erosion, but not the overall channel size. Second is the idea that the lateral fluid stress profile in a straight channel is representative of the spatially-averaged flow over many cross sections in a curved channel. The uniform flow approximation for boundary stress, $\tau_{b}=\rho g H_{b f} S$, can only be applied over length scales significantly larger than individual bends; as pointed out by Dietrich et al. [21], it is the "zero-order stress model". Higher-order behaviors like flow around bends produce stresses that vary spatially above and below the average. This allows erosion (deposition) on the outside (inside) of meander bends, and associated lateral grain-size sorting, while maintaining a stable channel geometry on average [21,22]. Thus, we propose that the Parker theory is a mean field model [23] that describes the time- and space-averaged geometry of natural gravel-bed rivers. As such, the predicted stable channel in the theory represents a statistically-stable average state for a natural river; the model says nothing about the nature of variation around that mean. To illustrate, we consider a reach of the Lochsa River, a gravel-bedded meandering river in Idaho $\left(Q_{b f}=446 \mathrm{~m}^{3} \mathrm{~s}^{-1}, D_{50}=0.15 \mathrm{~m}\right.$, $\left.S=0.0023, \tau_{c}=62.3 \mathrm{~Pa}\right)[13]$. Although there is significant variation in channel width about the mean value $\left(\left\langle W_{b f}\right\rangle=61.4 \pm 9.6\right.$ $\mathrm{m})$, the latter is within $8 \%$ of the value predicted by approximating the river as a straight, trapezoidal channel with uniform grain size, constant discharge and stable banks (Fig. 1C.).

Having shown that dynamic rivers are compatible with the Parker theory, we now pursue the generalization of the latter to the threshold limiting material model. We examine a global data set of river hydraulic geometry [24, 17, 13, 19] that spans a wide range of parameter space: $0.01 \leq D_{50} \leq 700 \mathrm{~mm} ; 8.75 e-06 \leq S \leq 0.35$; and $0.2 \leq Q_{b f} \leq 216,340 \mathrm{~m}^{3} / \mathrm{s}$. For gravel-bed rivers having $D_{50}>1 \mathrm{~cm}$, we see that bankfull fluid stresses cluster around the entrainment threshold estimated for river-bed sediments using the Shields curve (Fig. 2A). The significant scatter is likely due to site-specific controls on $\tau_{c}$ that are not accounted for with the Shields estimate; the variance in values of $\tau_{b} / \tau_{c}$ for gravel-bed rivers is greatly reduced when empirical measurements for $\tau_{c}$ are used $[13,14]$. For fine-grained rivers with $D_{50}<1 \mathrm{~cm}$, however, we see rivers peel off of the Shields curve; the smaller the river-bed grain size, the larger bankfull shear stress deviates from the threshold expectation (i.e, $\tau_{b f} / \tau_{c}>>1$ ) [25, 6, 19].

We infer that this departure, which occurs for bankfull shear stress values of order $\tau_{b f} \sim 10^{1} \mathrm{~Pa}$, represents the point where $\tau_{c}$ of cohesive banks becomes larger than $\tau_{c}$ of non-cohesive bed sediments, on average. This corresponds roughly to the range of fluid entrainment stresses $\left(6 \leq \tau_{c} \leq 9 \mathrm{~Pa}\right)$ that we have measured in the laboratory for sand/kaolinite-clay mixtures $(40-100 \%$ clay) [20] meant to represent cohesive river banks (Fig. 2A) [20]. Similar to gravel-bed rivers, we hypothesize that much of the scatter in the fine-grained rivers is related to site-specific variation in $\tau_{c}$ - though for the bank-toe material, rather than the bed. Next, we examine the distribution of fluid shear velocity, $U^{*}=\sqrt{\tau_{b} / \rho}$, for flows exceeding bankfull. Phillips and Jerolmack [13] posited that maintenance of a stable average channel geometry requires that $U^{*}$ values exceeding bankfull ( $\left.U_{b f}^{*}\right)$ drop off rapidly, and showed for gravel-bedded rivers that this drop off is exponential. While $U^{*}$ distributions for fine-grained rivers vary widely, normalizing each distribution by $U_{b f}^{*}$ reveals a trend that is identical to gravel-bedded rivers (Fig. 2B, C), for which $U_{b f}^{*} \approx 1.1 U_{c}^{*}$ (equivalent to $\tau_{b f} \approx 1.2 \tau_{c}$; i.e., the Parker closure). For the fine-grained rivers we do not know $U_{c}^{*}$ of the cohesive and/or vegetated banks. If the threshold limiting material model is correct, we may use the relation $U_{b f}^{*} \approx 1.1 U_{c}^{*}$ to infer that the range of entrainment stresses for bank materials is $3 \leq \tau_{c} \leq 10 \mathrm{~Pa}$. These values are reasonable considering reported ranges for muddy river banks in the literature [19, 20, 26, 27]. With this tentative support for the threshold limiting model, we test its ability to predict the width of all of the alluvial rivers in the global dataset, as a function of the imposed parameters slope and discharge. Predictive use of equations 1 and 2 requires assuming values for $C_{f}$ and $\tau_{c}$. For gravel-bedded rivers $\left(D_{50}>1 \mathrm{~cm}\right)$ we apply a constant $C_{f}=8.69$ that is the average value of those channels, while $\tau_{c}$ for each river is determined using the Shields curve [15]. For fine-grained rivers $\left(D_{50}<1 \mathrm{~cm}\right)$, where we assume that bank cohesion is limiting, we assign a constant $\tau_{c}=8 \mathrm{~Pa}$ that is representative of sand-clay mixtures [20], and an average $C_{f}=11.12$. Modelled channel widths cluster around measured values (Fig. 2D) for the entire dataset, with fine-grained rivers plotting right on top of gravel-bedded rivers. This demonstrates that the 


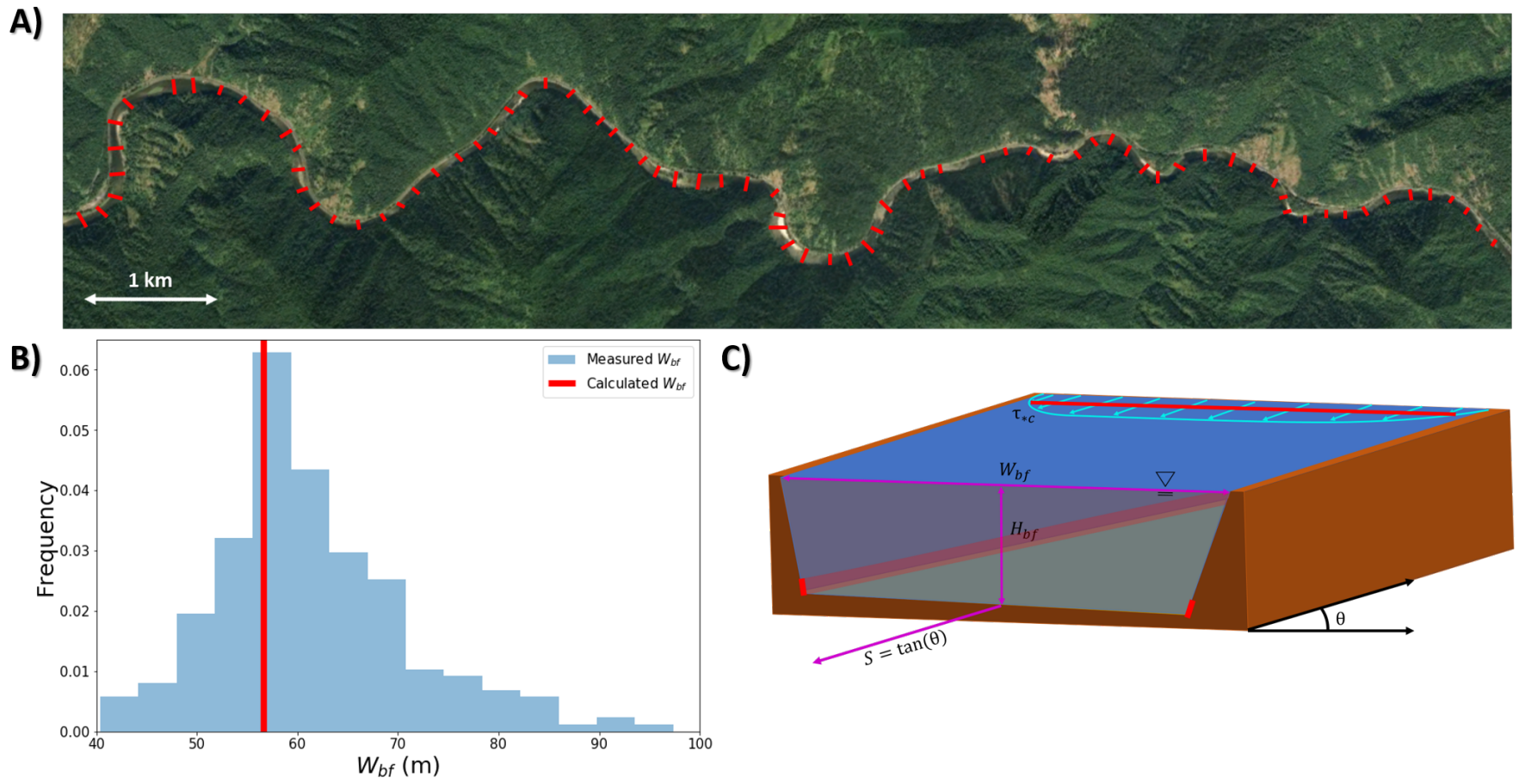

Figure 1: Demonstration of the mean field channel model. A) The Lochsa River, Idaho, USA. Red lines indicate approximately every third measured $W_{b f}$ from Google Earth (Image Source: Google Earth). B) Histogram of $W_{b} f(\mathrm{~N}=230)$. Red line indicates calculated $W_{b f}$ from Eq. 1. C)Schematic of an idealized straight, trapezoidal channel. Cyan lines at surface illustrate lateral boundary fluid-shear stress profile across the channel, $\tau_{b f}$. Red lines at the bank toe show the location where bed and bank materials meet. Horizontal red line intersecting the cyan velocity profile indicates $\tau_{c}$ of the threshold-limiting material. For the Parker model, $\tau_{b f}=\tau_{c}$ at the bank toe and $\tau_{b f}=1.2 \tau_{c}$ in the channel center.

first-order trend in channel hydraulic geometry may be predicted using the threshold limiting material model, assuming a fixed threshold stress for fine-grained rivers.

\section{Field CASE Study}

The global dataset provides several pieces of compelling, but indirect, evidence for the threshold limiting material model. A direct test requires in-situ measurement of the fluid entrainment threshold of bank-toe materials, in a river with a sand bed and cohesive banks. Up to now, existing methods were either too unwieldy or too indirect to determine $\tau_{c}$ at targeted locations in a channel. We have developed a new instrument, the Mudbuster, that is specifically designed to overcome these shortcomings [20]. The Mudbuster imposes an impeller-driven, rotational shear flow on a 18-cm diameter region of a river bed, and gradually increases the fluid shear stress until turbidity in the fluid column above the bed spikes — which is taken to be the entrainment threshold $\tau_{c}$. The principle, design, calibration and testing of the Mudbuster are reported elsewhere [20]. Here we report its first field deployment on the Mullica River, a sinuous and single-thread sand-bedded river $\left(D_{50} \approx 0.4 \mathrm{~mm}\right.$; see Methods, Supplementary Fig. 4) with muddy banks, that is located in the Pine Barrens within the New Jersey coastal plain (Fig. 3). We selected a 150m reach of the river $\left(Q_{b f} \approx 4.5 \mathrm{~m}^{3} \mathrm{~s}^{-1}, S=0.0008, W_{b f} \approx 5 \mathrm{~m}, H_{b f} \approx 1.2 \mathrm{~m}\right.$; see Methods, Supplementary Fig. 5) in which vegetation rooting depths were shallow compared to channel depth, in order to isolate sediment cohesion effects that could be measured directly with the Mudbuster. We surveyed 18 channel cross sections spaced roughly one channel-width apart to determine $\tau_{b f}$, and measured $\tau_{c}$ of the bank-toe material at each station (see Methods). The average value $\tau_{c}=4.5 \mathrm{~Pa}$ for bank-toe material (see Supplementary Materials) is over ten times larger than $\tau_{c}$ for non-cohesive sand $\left(\tau_{c}=0.3 \mathrm{~Pa}\right.$ [20]). We find that all 18 cross sections are close to $\tau_{b}=1.2 \tau_{c}$, with no cross section showing a bankfull shear stress larger than 1.5 times critical. These results confirm that, when the local entrainment threshold of cohesive banks is properly characterized, the sand-bedded Mullica River is a near-threshold channel for the threshold-limiting bank-toe material, but well above threshold for the sand bed. We view this as a direct confirmation of the threshold limiting material model. 

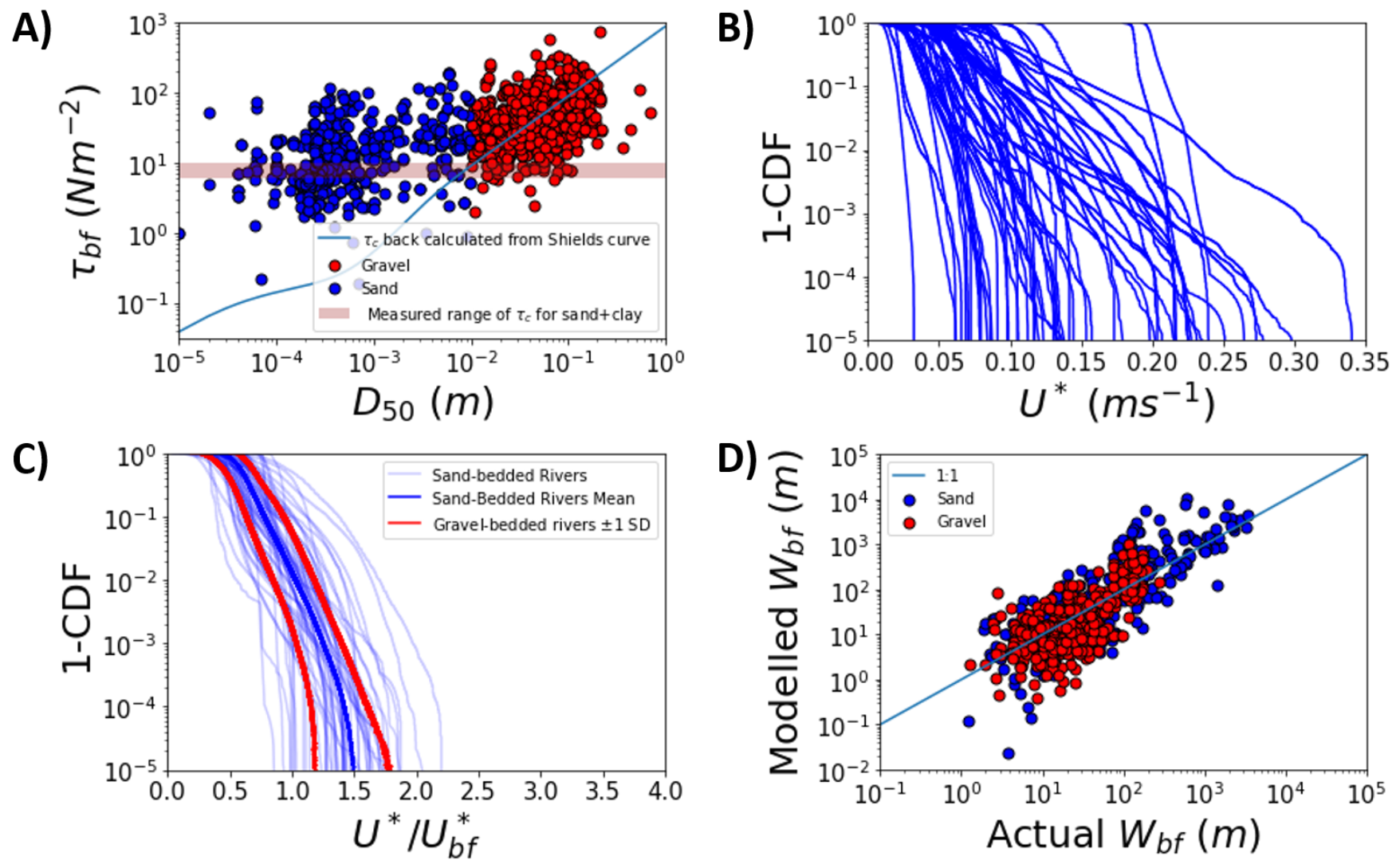

Figure 2: Flow and geometry conditions for the global river data. A) Bankfull shear stress $\tau_{b f}$ against median grain size $D_{50}$ for gravel-bedded $(D>1 \mathrm{~cm})$ and fine-grained $(D<1 \mathrm{~cm})$ rivers. Blue line is $\tau_{c}$ determined from bed $D_{50}$ based on the Shields curve [15]. Pink band shows our experimentally-determined range of $\tau_{c}$ for sand-clay mixtures [20]. Note that gravel-bedded rivers generally follow the Shields curve indicating bed-sediment control, while fine-grained rivers are consistent with cohesive bank control. B) $U^{*}$ magnitude-frequency distribution for a subset of fine-grained rivers in the global dataset $(n=56)$, showing high variability. C) The same as (B) but normalized by $U_{b f}^{*}$ for each river. Data collapse along a single curve; the dark blue line is the mean curve of fine-grained rivers, while red lines show standard deviation of gravel-bedded rivers [13] which are nearly identical to the fine-grained dataset. D) Modelled $W_{b f}$ using Eq. 1 vs. measured $W_{b f}$ values for all rivers in the global dataset.

\section{Planform Morphology}

Because of the influence of $\tau_{c}$ on channel width (Eq. 1) and depth (Eq. 2), we anticipate that the threshold-limiting material will exert a first-order control on channel planform morphology. Indeed, laboratory experiments examining self-formed sand rivers have induced a transition from braiding to single-thread channels, by enhancing bank strength through the addition of vegetation [28] and/or cohesive sediment [29]. Braiding is associated with channels that have large aspect ratios, $W_{b f} / H_{b f}>50$ [30]. A hydrodynamic stability analysis [31] predicts the transition from single-threaded to multiple-threaded (braided) planform morphologies as a function of $Q_{b f}, S, W_{b f}$, and $H_{b f}$. Using our Eq. 1 and 2, we recast the hydrodynamic stability criterion, $\epsilon$, in terms of the threshold limiting stress $\tau_{c}$ :

$$
\epsilon=\frac{Q_{b f} S^{5 / 2} g^{2} \rho^{5 / 2}}{\pi C_{f}^{2}\left(1.2 \tau_{c}\right)^{5 / 2}},
$$

where we expect braiding for $\epsilon>1$, and a single-thread morphology for $\epsilon<1$ [31]. Our global dataset is composed almost exclusively of US Geological Survey gauging stations placed in single-threaded channels, and should therefore plot overwhelmingly below the $\epsilon=1$ plane in the phase space of the imposed variables $Q_{b f}, S$ and $\tau_{c}$ (Fig. 4C). We compute $\epsilon$ for all rivers (Eq. 3), using the Shields curve to determine $\tau_{c}$ and a fixed global average value $C_{f}=9.74$ (minimal overall variation between gravel and sand-bedded channels, Fig. S1). Almost all of the gravel rivers (392/406) plot below the $\epsilon=1$ plane; i.e., the expected morphology agrees with observations. In contrast, most of the fine-grained rivers (264/305) plot above the $\epsilon=1$ plane; i.e., the predicted braided morphology is not what is observed. Assuming a representative cohesive bank entrainment threshold of $\tau_{c}=8$ 

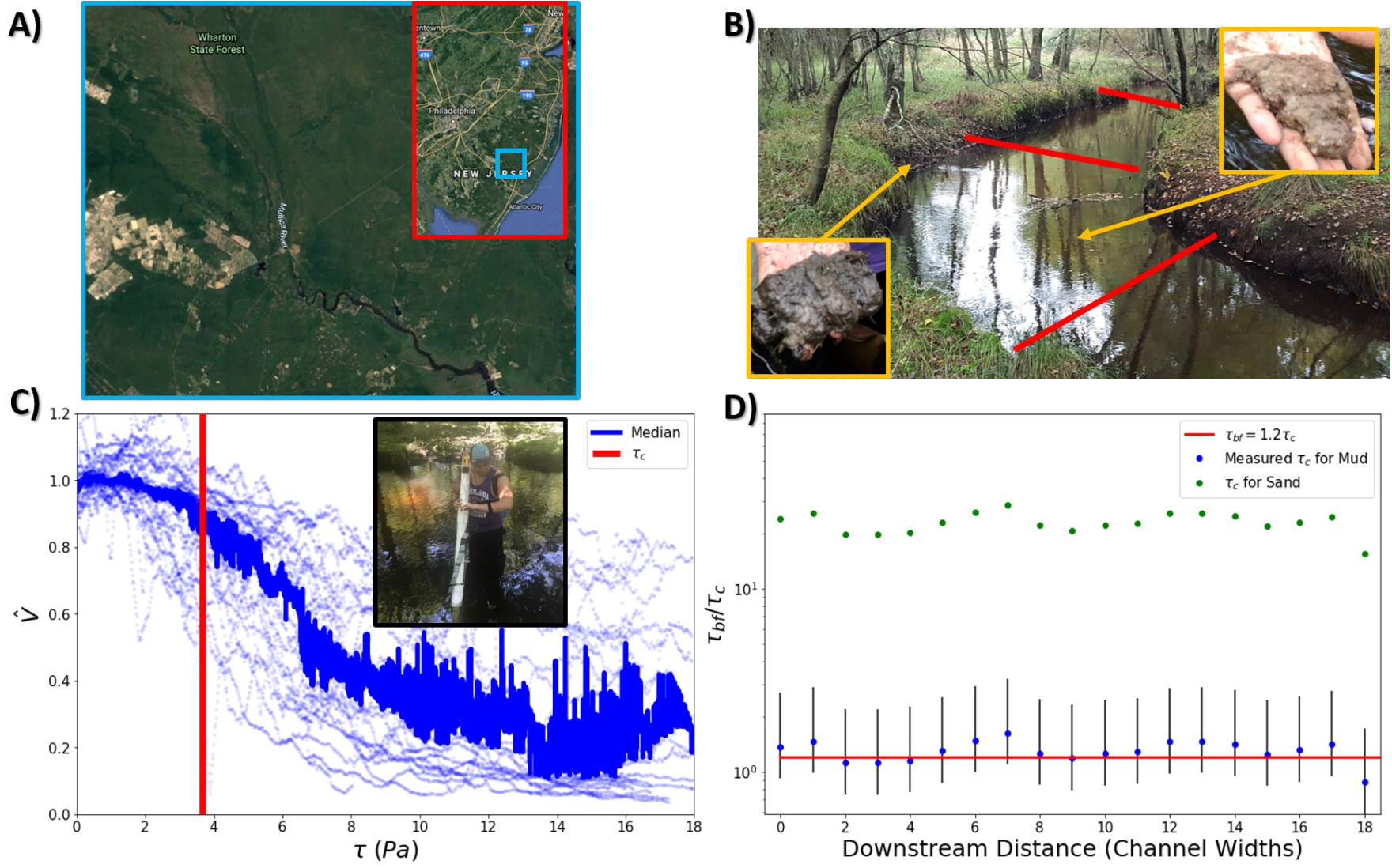

Figure 3: Threshold limiting material case study. A) Location of the Mullica river watershed in Wharton State Forest in the New Jersey coastal plain (Image source: Google Earth). B) Portion of the surveyed reach of the Mullica river. Red lines mark surveyed cross sections. Muddy bank and bed materials shown in bottom left and top right, respectively. C) Mudbuster measurements used to determine $\tau_{c}$ of bank-toe material. The fluid shear stress $\tau$ is gradually ramped up, while turbidity is measured as a voltage drop normalized by the initial voltage prior to shearing, $\hat{V}$ [20]. This 2D histogram (colorbar shows counts in each bin) is derived from 28 measurements of bank-toe material; the red line shows the mean value $\tau_{c}=4.5 \mathrm{~Pa}$ determined from these data (see Methods). Inset: Implementation of the "Mudbuster" to measure $\tau_{c}$ of bank-toe material; device is controlled using a smart phone via a Bluetooth connection [20]. D) Values of $\tau_{b f} / \tau_{c}$ for all 18 cross sections, where $\tau_{c}=4.5 \mathrm{~Pa}$ was determined from the average of bank-toe material measurements; the Parker model value $\tau_{b f} / \tau_{c}=1.2$ is shown for reference, and error bars indicate \pm 1 standard deviation. Green points show $\tau_{b f} / \tau_{c}>>1$ for sand-bedded material, indicating control of cohesive bank-toe material on channel geometry.

$\mathrm{Pa}$, however, shifts almost all of the fine-grained rivers (279/305) into the single-threaded regime - in compliance with their observed morphology. The assumption of a fixed $\tau_{c}$ for bank materials is, of course, a crude assumption. We find that improved knowledge of site-specific $\tau_{c}$ results in better predictions (Fig. 4B). We consider the case of the Mullica where $\tau_{c}$ was directly measured, and some channels in the Selenga Delta [32] and several rivers studied by Schumm [33] where $\tau_{c}$ may be roughly estimated from reported silt and clay content using an empirical correlation function [34]. All of these rivers are sand-bed rivers with cohesive channel banks, and plot well into the braided regime if $\tau_{c}$ for bed material is used. When $\tau_{c}$ for the threshold-limiting bank material is used, however, these rivers shift into the morphospace compliant with their observed morphology. These results provide an explanation for the observation that single-threaded, sand-bedded rivers in nature and the laboratory [28] seem to require cohesive and/or vegetated banks. Finally, we suggest that the downstream transition from a gravel- to sand-bed river may lead to a shift from bed to bank control, that may explain downstream changes in planform morphology such as that seen on the Fraser River (Fig. S2).

\section{Conclusions AND OutLooK}

Our findings indicate that average alluvial river geometry may be predicted with knowledge of four parameters: bankfull discharge, slope, friction factor, and entrainment stress of the threshold limiting material. Although friction factor varies among rivers, this variation is not systematic with any other parameter and is substantially less than the other controlling variables [19] (Fig. S1). 


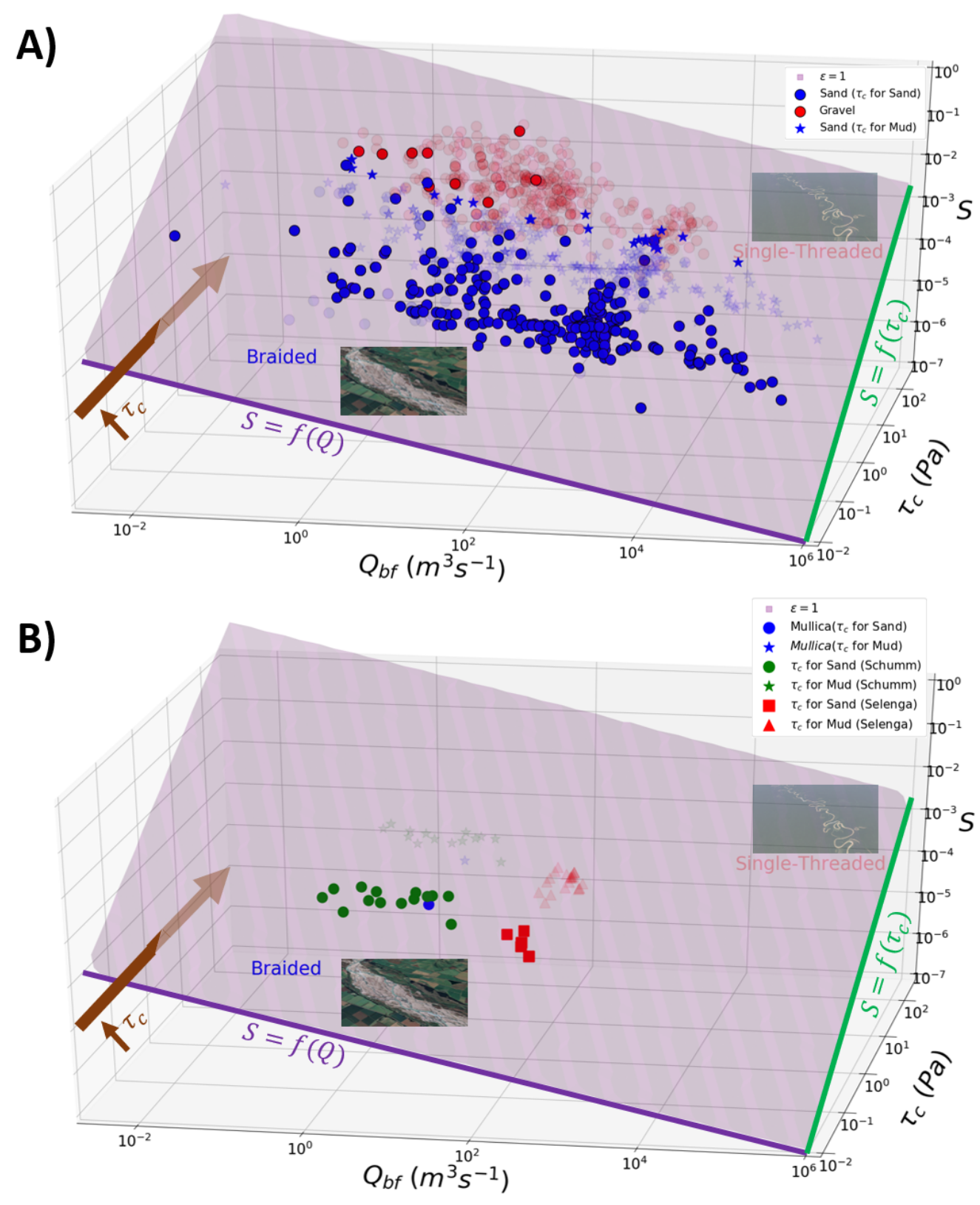

Figure 4: Planform pattern morphospace of alluvial rivers in the global dataset. A) Global data set: Hydrodynamic stability criterion $\epsilon=1$, shown by the plane, shows the expected separation of braided from single-threaded channels in the parameter space of discharge $Q_{b f}$, slope $S$ and entrainment threshold $\tau_{c}$. Inset images show typical braided morphology of the Waimakariri River, and single-threaded meandering Rio Purus (Image Sources: Google Earth). Virtually all rivers in this dataset should plot as single-threaded. When $\tau_{c}$ for bed-sediment $D_{50}$ determined from the Shields curve is used, gravel-bedded rivers almost invariably plot as single-thread, but fine-grained rivers are mostly braided. Using a representative $\tau_{c}=8 \mathrm{~Pa}$ for mud instead, fine-grained rivers shift to the correct single-threaded morphospace. Purple line highlights $Q_{b f}-S$ relation for a given $\tau_{c}$, which follows the classic empirical delineation [35]. Green line indicates $\tau_{c}-S$ relations for a given $Q_{b f}$. Brown arrow shows how increasing $\tau_{c}$ can drive migration across the $\epsilon=1$ plane. B) Additional single-threaded rivers with sand beds and muddy banks, in which $\tau_{c}$ of bank-toe was measured (Mullica) or could be estimated from reported descriptions of bank material [34] (Schumm and Selenga). Selenga River delta channels were selected so as to be outside of the range of the backwater effect [32], and additional rivers were reported by Schumm [36]. 
More refined models for determining $C_{f}$ may improve channel geometry predictions; to first order, however, one may assume $C_{f} \sim 10^{1}$. Improved knowledge of $\tau_{c}$ leads to more accurate predictions of bankfull width and depth, echoing other recent studies that have pointed out the need for site-specific measurements of threshold $[13,14]$. Results demonstrate that the Parker closure for gravel rivers can be extended to finer-grained systems by considering the threshold limiting bank material. This model can describe the average geometry of dynamic alluvial rivers in nature, including those that transport bed sediment far above threshold. This framework also illustrates how changing river-bank composition, as well as interactions with biological forcings (e.g. biofilms, tree roots, etc.) that may induce an overall change in bank stability, may induce a change in planform morphology from braiding to meandering, which has implications for interpreting alluvial river deposits on Earth and Mars [37, 38, 39, 40]. The simple model equations 1 and 2 may find immediate use in engineering applications, where management and restoration of river channels requires an understanding of the relations between hydraulics and channel geometry [1]. The apparent success of the threshold limiting model, however, raises other intriguing questions. This approach is purely hydraulic: channel geometry is determined by the conveyance capacity of water $\left(Q_{b f}, S, C_{f}\right)$, and the entrainment threshold of the channel margins $\left(\tau_{c}\right)$. While sediment grain size influences $\tau_{c}$, the sediment discharge supplied to the channel, $Q_{s}$, does not appear anywhere in this formulation. Sediment supply has been proposed to influence channel geometry [11] and also planform morphology [30]. We posit that there is in fact an indirect influence of sediment supply, through its modulation of slope. On engineering (decadal) timescales, slope is often considered an independent variable because its timescale of adjustment is much slower than width and depth [41, 13]. Over longer timescales, however, threshold channel models indicate that $S \sim Q_{s} / Q_{b f}[41,16]$. We suggest that changing sediment supply rate $Q_{s}$ has an indirect and slow influence on channel geometry, through re-grading of river slope. If changes in supply influence grain size, however - either by changing the size fed to channels, or by inducing armoring of the river bed [41, 11] — then they will have a more direct and immediate impact on geometry by altering $\tau_{c}$.

\section{Materials AND Methods}

We utilised Google Earth's ruler tool to collect measurements of $W_{b f}$ for the Lochsa River. Images of the channel were not necessarily taken at bankfull conditions, so bankfull extent was estimated based on color variations with an approximate pixel resolution of $0.65 \mathrm{~m}$. Measurements of $Q_{b f}, S, D_{50}$, and $\tau_{c}$ for the Lochsa River were reported in the Supplementary Material of Phillips and Jerolmack, 2016 [13]. The global dataset we utilised has been presented elsewhere [19]. It contains measured channel geometry and discharge values associated with bankfull flow; i.e., when the channel is completely filled with water. Friction factor $C_{f}$ for each river was computed using a Darcy-Weisbach flow resistance relation (Supplementary Material). Estimates for the threshold entrainment stress $\left(\tau_{c}\right)$ of non-cohesive sediment were determined from an empirical fit to the Shields curve [15], which represents the combined fluid drag and lift forces required to overcome particle friction. Channel geometry and bank composition data for rivers presented in Figure 4B were taken from reported values in the associated publications [32, 33]. Estimates of threshold entrainment stress for cohesive sediment in these additional rivers were calculated using an empirical relation between $\tau_{c}$ and $\%$ silt-clay [34].

Data to produce the hydrograph magnitude-frequency curves (Fig. 2B,C) were collected from the USGS website and analysed using code and methodology developed by Phillips and Jerolmack, 2016 [13]. Gravel-bedded rivers were the same rivers analysed by Phillips and Jerolmack, 2016 [13]; we added fine-grained rivers from a global data set [19] for which sufficient data were available. Because of heavy overlap between the gravel- and fine-grained rivers, only the mean for fine-grained rivers and standard deviation for gravel-bedded rivers are shown.

The Mullica River was selected for field work due to its proximity, and desired bed and bank properties for the study. Channel slope for the studied reach was determined over a 6-km stretch of river using a Trimble ProXH differential GPS sampling at 1 $\mathrm{Hz}$ from a boat (Supplementary Fig. 3). Bed grain size was relatively uniform throughout the reach, and was measured using a CAMSIZER (Supplementary Fig. 4). We surveyed bankfull channel width and depth at 18 cross sections using a laser range finder (Supplementary Fig. 5). Calculations of bankfull stress at each location utilised the bankfull depth at each cross section, and the reach-averaged slope. At each cross section, the edge of the bank was identified in the field. Bank-toe erodibility measurements were made using the Mudbuster in-situ erodibility tester, following the procedures and calibrations outlined in another paper [20]. At each cross section, four measurements of $\tau_{c}$ were taken at the toe of the channel bank. Fluid shear stress is systematically increased with the Mudbuster while turbidity is measured using two photo-diodes. Increased turbidity measures as a voltage drop, which is expected to occur abruptly at a threshold fluid stress. While each measurement showed a voltage decline with increasing applied shear stress, determining a precise threshold was challenging due to noise (Fig. S6). Variations of the voltage drop from measurements within a single cross section, and measurements among different cross sections, were of comparable magnitude (Supplementary Fig. 6). Accordingly, we lumped together all voltage drop curves to produce a more robust statistical determination of the average $\tau_{c}$ for all cross sections (Fig. 4C). This is the reach-averaged value $\tau_{c}=4.5 \mathrm{~Pa}$ reported in the text.

\section{REFERENCES}

[1] Martin W Doyle, Doug Shields, Karin F Boyd, Peter B Skidmore, and DeWitt Dominick. Channel-forming discharge selection in river restoration design. Journal of Hydraulic Engineering, 133(7):831-837, 2007. 
[2] Peter Wilcock. Friction between science and practice: The case of river restoration. Eos, Transactions American Geophysical Union, 78(41):454-454, 1997.

[3] Luna Bergere Leopold and Thomas Maddock. The hydraulic geometry of stream channels and some physiographic implications, volume 252. US Government Printing Office, 1953.

[4] Andrew P Nicholas. Modelling the continuum of river channel patterns. Earth Surface Processes and Landforms, 38(10): 1187-1196, 2013.

[5] National Research Council et al. Landscapes on the edge: New horizons for research on Earth's surface. national academies Press, 2010.

[6] François Métivier, Eric Lajeunesse, and Olivier Devauchelle. Laboratory rivers: Lacey's law, threshold theory, and channel stability. Earth Surface Dynamics, 5(1):187-198, 2017. doi: 10.5194/esurf-5-187-2017.

[7] Gerald Lacey. Stable channels in alluvium (includes appendices). In Minutes of the Proceedings of the Institution of Civil Engineers, volume 229, pages 259-292. Thomas Telford-ICE Virtual Library, 1930.

[8] Gary Parker. Self-formed straight rivers with equilibrium banks and mobile bed. part 2. the gravel river. Journal of Fluid mechanics, 89(1):127-146, 1978. doi: 10.1017/S0022112078002505.

[9] Michael Church. Bed material transport and the morphology of alluvial river channels. Annu. Rev. Earth Planet. Sci., 34: 325-354, 2006. doi: 10.1146/annurev.earth.33.092203.122721.

[10] SA Schumm and HR Khan. Experimental study of channel patterns. Geological Society of America Bulletin, 83(6): 1755-1770, 1972.

[11] Allison M Pfeiffer, Noah J Finnegan, and Jane K Willenbring. Sediment supply controls equilibrium channel geometry in gravel rivers. Proceedings of the National Academy of Sciences, 114(13):3346-3351, 2017.

[12] Brett C Eaton and Michael Church. Predicting downstream hydraulic geometry: a test of rational regime theory. Journal of Geophysical Research: Earth Surface, 112(F3025), 2007. doi: 10.1029/2006JF000734.

[13] Colin B Phillips and Douglas J Jerolmack. Self-organization of river channels as a critical filter on climate signals. Science, 352(6286):694-697, 2016. doi: 10.1126/science.aad3348.

[14] CB Phillips and DJ Jerolmack. Bankfull transport capacity and the threshold of motion in coarse-grained rivers. Water Resources Research, 2019.

[15] Leo C van Rijn. Initiation of motion and suspension; critical bed-shear stress for sand-mud mixtures. 2016. URL www. leovanrijn-sediment. com.

[16] Gary Parker. Self-formed straight rivers with equilibrium banks and mobile bed. part 1. the sand-silt river. Journal of Fluid Mechanics, 89(1):109-125, 1978.

[17] Chuan Li, Matthew J Czapiga, Esther C Eke, Enrica Viparelli, and Gary Parker. Variable shields number model for river bankfull geometry: bankfull shear velocity is viscosity-dependent but grain size-independent. Journal of Hydraulic Research, 53(1):36-48, 2015.

[18] Kumar Gaurav, François Métivier, Olivier Devauchelle, Rajiv Sinha, Hugo Chauvet, Morgane Houssais, and Hélène Bouquerel. Morphology of the kosi megafan channels. Earth Surface Dynamics, 3(3):321-331, 2015. doi: 10.5194/ esurf-3-321-2015.

[19] Kieran BJ Dunne and Douglas J Jerolmack. Evidence of, and a proposed explanation for, bimodal transport states in alluvial rivers. Earth Surface Dynamics, 6(3):583-594, 2018. doi: 10.5194/esurf-6-583-2018.

[20] Kieran B.J. Dunne, Paulo E. Arratia, and Doulgas J. Jerolmack. A new method for in-situ measurement of the erosion threshold of river channels. 2019.

[21] William E Dietrich, J Dungan Smith, and Thomas Dunne. Flow and sediment transport in a sand bedded meander. The Journal of Geology, 87(3):305-315, 1979.

[22] Jordan A Clayton and John Pitlick. Spatial and temporal variations in bed load transport intensity in a gravel bed river bend. Water Resources Research, 43(2), 2007.

[23] Leo P Kadanoff. More is the same; phase transitions and mean field theories. Journal of Statistical Physics, 137(5-6):777, 2009.

[24] SM Trampush, S Huzurbazar, and Brandon McElroy. Empirical assessment of theory for bankfull characteristics of alluvial channels. Water Resources Research, 50(12):9211-9220, 2014.

[25] Gregory V Wilkerson and Gary Parker. Physical basis for quasi-universal relationships describing bankfull hydraulic geometry of sand-bed rivers. Journal of Hydraulic Engineering, 137(7):739-753, 2010.

[26] GJ Hanson and Andrew Simon. Erodibility of cohesive streambeds in the loess area of the midwestern usa. Hydrological processes, 15(1):23-38, 2001. doi: 10.1002/hyp.149. 
[27] Candice R Constantine, Thomas Dunne, and Gregory J Hanson. Examining the physical meaning of the bank erosion coefficient used in meander migration modeling. Geomorphology, 106(3-4):242-252, 2009. doi: 10.1016/j.geomorph.2008. 11.002 .

[28] Michal Tal and Chris Paola. Dynamic single-thread channels maintained by the interaction of flow and vegetation. Geology, 35(4):347-350, 2007.

[29] Christian A Braudrick, William E Dietrich, Glen T Leverich, and Leonard S Sklar. Experimental evidence for the conditions necessary to sustain meandering in coarse-bedded rivers. Proceedings of the National Academy of Sciences, 106(40): 16936-16941, 2009.

[30] BC Eaton, Robert G Millar, and Sarah Davidson. Channel patterns: Braided, anabranching, and single-thread. Geomorphology, 120(3-4):353-364, 2010.

[31] Gary Parker. On the cause and characteristic scales of meandering and braiding in rivers. Journal of fluid mechanics, 76(3): 457-480, 1976. doi: 10.1017/S0022112076000748.

[32] Tian Y Dong, Jeffrey A Nittrouer, Matthew J Czapiga, Hongbo Ma, Brandon McElroy, Elena Il'icheva, Maksim Pavlov, Sergey Chalov, and Gary Parker. Roles of bank material in setting bankfull hydraulic geometry as informed by the selenga river delta, russia. Water Resources Research, 2019.

[33] SA Schumm. The shape of alluvial channels in relation to sediment type. USGS Prof. Pap, 1960.

[34] Jason P Julian and Raymond Torres. Hydraulic erosion of cohesive riverbanks. Geomorphology, 76(1-2):193-206, 2006. doi: 10.1016/j.geomorph.2005.11.003.

[35] Luna Bergere Leopold and Markley Gordon Wolman. River channel patterns: braided, meandering, and straight. US Government Printing Office, 1957.

[36] Stanley A Schumm. Sinuosity of alluvial rivers on the great plains. Geological Society of America Bulletin, 74(9):1089-1100, 1963. doi: 10.1130/0016-7606(1963)74[1089:SOAROT]2.0.CO;2.

[37] Vamsi Ganti, Alexander C Whittaker, Michael P Lamb, and Woodward W Fischer. Low-gradient, single-threaded rivers prior to greening of the continents. Proceedings of the National Academy of Sciences, 116(24):11652-11657, 2019.

[38] Alessandro Ielpi and Mathieu GA Lapôtre. A tenfold slowdown in river meander migration driven by plant life. Nature Geoscience, 13(1):82-86, 2020.

[39] Neil S Davies, Martin R Gibling, and Michael C Rygel. Alluvial facies evolution during the palaeozoic greening of the continents: case studies, conceptual models and modern analogues. Sedimentology, 58(1):220-258, 2011.

[40] Alessandro Ielpi and Mathieu GA Lapôtre. Biotic forcing militates against river meandering in the modern bonneville basin of utah. Sedimentology, 2018.

[41] Chris Paola, Gary Parker, Rebecca Seal, Sanjiv K Sinha, John B Southard, and Peter R Wilcock. Downstream fining by selective deposition in a laboratory flume. Science, 258(5089):1757-1760, 1992.

\section{AUTHOR CONTRIBUTIONS STATEMENT}

K.B.J.D performed the research and analysed the data, D.J.J. supervised the research, and both authors wrote the paper.

\section{ACKNOWLEDGEMENTS}

We thank James Pizzuto, Jeffrey Nittrouer, and Colin Phillips for their feedback that helped us frame aspects of this paper. We thank Colin Phillips for sharing his hydrograph analysis code. We thank Qin Zhang and Jiyeux Seok for their assistance carrying out the field investigation. The research was sponsored by the Army Research Laboratory and the National Science Foundation, and was accomplished under grant numbers W911-NF-16-1-0290 and 1734355, respectively. All data generated during this study are displayed in the supplementary information files and available for download at this OSF data repository: https://osf.io/j7xn6/. 